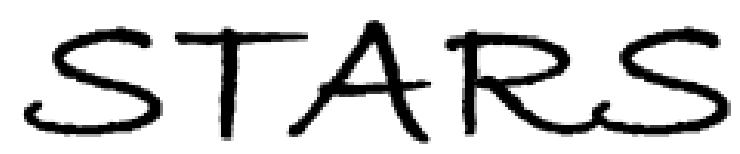

University of Central Florida

STARS

$9-1-2013$

\title{
One Experience and Multiple Reviews: The Case of Upscale U.S. Hotels
}

\author{
Edwin Torres \\ University of Central Florida, edwin.torres@ucf.edu \\ Howard Adler \\ Xinran Lehto \\ Carl Behnke \\ Li Miao
}

Part of the Hospitality Administration and Management Commons, and the Tourism and Travel Commons

Find similar works at: https://stars.library.ucf.edu/rosenscholar

University of Central Florida Libraries http://library.ucf.edu

This Paper is brought to you for free and open access by the Rosen College of Hospitality Management at STARS. It has been accepted for inclusion in Rosen Faculty Scholarship and Creative Works by an authorized administrator of STARS. For more information, please contact STARS@ucf.edu.

\section{Original Citation}

Torres, E. , Adlerh, H., Lehto, X., Behnke, C., Miao, L. (2013). One experience and multiple reviews: The case of upscale US Hotels. Tourism Review, 68 (3), 3-20.

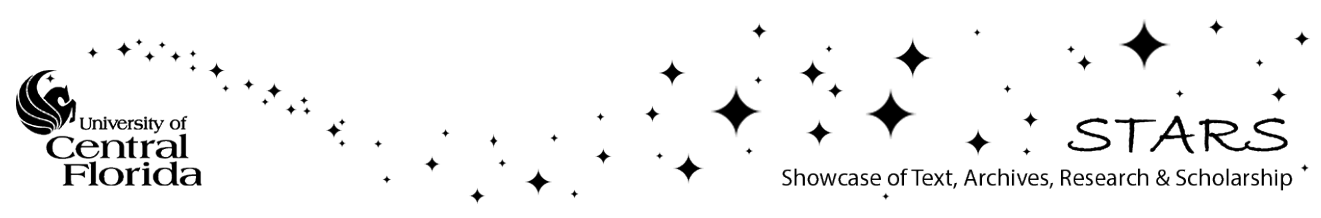




\title{
One experience and multiple reviews: The case of upscale U.S. hotels
}

\begin{abstract}
Purpose - The present study aimed to understand the relationships between the various kinds of feedback received by hospitality operators. Information from guests, experts, and internal sources are often received, valued, and processed in various ways. The researchers sought to further explore the usage of such feedback and implications for theory and practice.
\end{abstract}

Design/methodology/approach - A survey was sent to hotel General Managers of four and five diamond properties around the United States using the listing of the American Automobile Association (AAA). A total of 140 responses were received. The researchers utilized correlations and canonical correlation analysis to help understand the relationships among the variables.

Findings - The results of the study revealed moderate to strong correlations between improvement in consumer-generated feedback and customer satisfaction; between improvement in AAA ratings and customer satisfaction and mystery shopping scores. There were also moderate to high correlations among value placed in consumer-generated and that placed on other electronic forms of electronic feedback such as social networking, blogs, and online travel agency feedback. Canonical correlation was also performed among the variables in the various correlation matrices. Two statistically significant dimensions emerged. The most influential variables in the first dimension were value placed on TripAdvisor and value placed on meeting planner feedback. The second dimension, featured three influential variables: value placed on reviews in TripAdvisor, value placed on social networking, and perceived improvement in consumer-generated ratings.

Research and Practical Implications - The present research revealed two distinct sets of General Managers: those who have a strong preference towards online feedback and those who place greater value in traditional sources of feedback such as letters from customers. Additionally, the researchers discovered some similarities between improvement in scores of experts and consumers. This in turn, points out to the existence of some universal aspects of service that appeal to both stakeholder groups. The different levels of value placed on various kinds of feedback points out to the need for tourism and hospitality operators to adopt a more comprehensive strategy to collect, analyze, and take appropriate actions based on such information.

Originality/value - The researchers contribute to the nascent literature on consumer-generated feedback by exploring its relationship to other variables. Furthermore, the study of various sources of feedback (i.e. guests, experts, and operators) is often studied separately in the tourism literature. It was the aim of this study to explore all of these together in order to better understand their relationships, value, and uses.

Keywords: Consumer generated feedback, Online Reviews, Customer satisfaction, TripAdvisor, Hotel rating systems 


\section{Introduction}

In the process of delivering and experiencing the hospitality and tourism product, various individuals play different roles. Operators typically create and deliver the experience. Experts typically bring forth specialized knowledge that can point out strengths and areas of opportunities. Finally, consumers can provide feedback on their perception of the services they received. In the tourism and hospitality literature, researchers have paid attention to each one of these subjects individually. One stream of research has focused on internal sources of feedback such as benchmarking, internal audits, and feedback from corporate managers (Behara \& Lemmink, 1997; Callan, 1990; McGaughey, 2002). Others have explored expert sources of feedback such as mystery shopping, and rating systems (Beck \& Miao, 2003; Narangajavana \& Hu, 2008; Su \& Sun, 2007). Yet, a third group of researchers has focused on consumer generated feedback (Cox, et al., 2009; Kasavana, et al., 2010, O'Connor, 2010; O'Mahony \& Smith, 2009; Schmallegger \& Carson, 2007; Senecal \& Nantel, 2004; Sparks \& Browning, 2011).

The existing literature has helped understand how each of these forms of feedback is generated and its potential impact on the tourism industries. However, more research is needed to understand the similarities, and differences between the three types of feedback. In light of this, the present research provides scholars additional insight as to the meaning, themes, relationships, and patterns of feedback. Additionally, practitioners could benefit from using an integrated approach to collect and analyze feedback in order to improve operational effectiveness. Indeed, practitioners in the hospitality and tourism industries have grown increasingly concerned about their image and reputation online. However, consumer generated feedback is often studied in isolation to other more traditional forms of feedback such as letters, E-Mails, and in-person complaints. Furthermore, consumer feedback is often studied in separate studies from those that explore the feedback of other stakeholders such as operators and experts. 
At the present time, there is little knowledge of the relationships between one form of feedback to the next. In other words, if consumers speak highly of a hotel, will experts rate the hotel highly as well? Or, would the perceptions of operators coincide with those of consumers and experts? In light of this, the present research sought to explore the correlations between the various sources of feedback. Given the present knowledge and seeking to expand on the body of literature as well as to provide new directions, the researchers proposed the following objectives:

- To examine the correlations between expert and consumer feedback

- To ascertain the differences in value placed on all sources of feedback by practitioners

- To explore the dimensionality of the various variables of interest through canonical correlation analysis

\section{Theory}

\section{$\underline{2.1 \text { Operator Perspectives }}$}

In order to explore the quality of the services operators provide, they often turn to various tools. One such tool is that of benchmarking. Such practice was developed by the Xerox corporation in 1979 and its use became widespread in the 1980's and 199's (Adebanjo, Abbas, \& Mann, 2010). Benchmarking can be defined as "a continuous quality improvement process in which an organization can assess its internal strengths and weaknesses, evaluate comparative advantages of leading competitors, identify best practices of industry functional leaders, and incorporate these findings into a strategic action plan geared to gain a position of superiority" (Min, 1996 as cited in Min, et al., 2002, pp. 303). In the past researchers have attempted to classify the various benchmarking practices. McGaughey (2002) classified benchmarking in three different forms: internal, external, and best practices. In contrast Behara and Lemmink (1997) proposed that benchmarking can be classified by what 
is being benchmarked and who is being benchmarked. Yet, another group of researchers proposed that benchmarking can be categorized as internal, competitive, and functional (Yasin and Zimerer, 1995).

In the hospitality and tourism industries benchmarking is frequently used to look at a competitor's pricing strategies, employment practices, and customer services among others. Researchers have conducted studies that identify companies with best practices based on competitive measures, human resource results, customer-related measures, and financial results (Enz and Siguaw, 2000). Additionally, benchmarking can help companies identify innovative practices to follow (Enz and Siguaw, 2003). Min et.al. (2002) proposed a dynamic model for benchmarking. Such a model allowed for the adjustment of customer expectations in various aspects of hotel performance over time. In spite of the usefulness of such a practice, firms can struggle to execute this. Some of the challenges they often encounter include: changing demand, limited resources, lacked of skilled labor, and lack of competitive benchmarking (Hwang \& Lockwood, 2006). Furthermore, some of the best practices that make an organization successful in one country might not necessarily work abroad (Yang \& Lu, 2006).

In addition to benchmarking hospitality and tourism operators often turn to their training and development programs as a means of ensuring service quality. Claver-Cortes, Pereira-Moliner, Tari, and Molina-Azorin (2007) studied to hotels that were examples of commitment to service. They found that such hotels often had advanced training and development systems. Furthermore Chand and Catou (2007) explored the relationship to between various human resource practices and service quality. They discovered that training and development efforts were highly correlated to service quality. Another human resource practice that can assist practitioners in attaining service quality is that of empowerment. Torres and Kline (2013) discovered that a customer, who had a problem elegantly corrected, especially if the business was not at fault, is likely to be a delighted customer. 
Internal feedback can also come from performing a quality audit. Such a process typically identifies sources of errors, determines the frequency of errors, assigns cost to such errors, determines the probability of their occurrence, and establishes some likely solutions. Luchars and Hinkin (1996) conducted a case analysis in a large hotel who successfully implemented this program. Another such tool is Six Sigma. This focuses on minimization of variation through metric measurement and statistics. One of the few companies in the tourism and hospitality industries to successfully implement such a system is Starwood Hotels and Resorts (Ante, 2007). Other forms to assess the quality of services may also entail using one of the various service quality measurements available such as SERVQUAL (Parasuraman, et al., 1988) and SERVPERF (Cronin and Taylor, 1992). SERVUQL evaluate expectations versus performance in five dimensions: tangibles, reliability, assurance, empathy and responsiveness (Parasuraman, et al., 1988). In contrast SERVPERF advocates for a performance-only approach (Cronin and Taylor, 1992).

In addition to the generic quality literature, hospitality researchers have addressed the subject of service quality in the various hospitality and tourism industries. Crick and Spencer (2011) called into question the applicability of general service models to specific industries, especially the hotel industry. Most of the research in service quality has stressed the existence of gaps between expectations and performance. As a contribution to this discussion, researchers Grobelna and Marciszewska (2013) proposed that the gaps between expectations and performance might be different for various demographics. Their study demonstrated that the greatest gaps existed among the well-educated, females, people with higher incomes and the elderly. Furthermore, leisure travelers had a higher gap as when compared to those who traveled for business.

A debate also exists as to the relationship between quality and satisfaction. Recently, it has been argued that service quality has been studied as either a separate variable or as an antecedent to 
satisfaction, as opposed to as part of an overall experience construct (Knuston, et al., 2010). Kim (2011) proposed a structural model whereby customer satisfaction mediates the perception of service quality and the intention to remain loyal. In a similar fashion, Mason and Nassivera (2013) stated that perceived quality (evaluation) leads to satisfaction (emotional response), which in turn leads to behavioral intention (reiteration). Carrillat, Jaramillo, and Mulkin (2009) sought to clarify the relationship between service quality and customer satisfaction by performing a meta- analysis of the impact of service quality. Their findings show that service quality has a large effect on customer satisfaction, attitudinal loyalty, and purchase intention. Wong and Fong (2010) explored the factors that lead to quality and satisfaction in the casino industry. They discovered that ambiance and quality had the greatest impact.

Salazar, Costa, and Rita (2010) stressed the importance of both research from consumers and non-consumers. Accordingly, "research from consumers tells us about a firm's strengths and weaknesses. Research from non-consumers tells us about competitor's performance and this can be used as a standard for comparison" (pg. 384). The present research stresses the importance of various stakeholders in order to obtain information about the quality of the services a hotel provides. Consequently, the similarities, differences, and patterns found from consumers, experts, and internal stakeholders can all contribute to the improvement of service quality.

\subsection{Expert Perspectives}

Practitioners occasionally seek the advice and feedback of people outside the organization to guide their quality practices. Experts such as mystery shoppers, consultants, professional raters, and travel writers. A question remains as to the similarities and differences in their evaluation of service providers, as compared to consumer or internal sources. In the hotel and restaurant industries, formalized rating systems exist. Su and Sun (2007) explored the hotel rating systems in the United States, United Kingdom, China and Taiwan. Narangajavana and Hu (2008) explored hotel rating systems 
in light of various service attributes. Rating systems can help practitioners by pointing out specific aspects of a venue's physical facilities or service that needs improvement in order to comply with a certain rating category. Additionally, having an outside perspective can provide information that might not seem obvious to those who work in the business on a daily basis.

Mystery shopping is yet another tool that is widely used in the hospitality and tourism industries. Many mystery shopping evaluations are conducted by trained inspectors from consulting firms (Beck and Miao, 2003). Such inspectors can have a very detailed checklist that ensures that various aspects of the product and service are in compliance with a universal set of standards. Mystery shoppers can help organizations by benchmarking their competitors, measuring service quality, identifying critical failure points, and ensuring training effectiveness (Van Der Wiele, et al., 2005). In addition to professional raters and mystery shoppers, other experts can also provide feedback to an organization. Callan (1990) conducted a study using travel writers in order to better understand service quality in the tourism industries.

Some organizations turn to various award schemes as a means to improve their quality. As an example of a company that followed this line of thinking, the Ritz Carlton hotel company attained the Malcolm Baldridge Quality Award. This is an award offered by the Department of Commerce of the United States government to companies who excel in their quality practices. In order to obtain this award, Ritz Carlton had to produce daily quality production reports, establish an early warning system to identify problems and impediments to service quality, establish customer satisfaction goals, and constantly obtain feedback from their customers (NISTD, n.d.). Another way to attain quality improvement is to obtain a quality certification such as the one offered by the International Organization for Standardization. ISO is very popular among manufacturing organizations. Accordingly, companies must document methods to monitor quality, frequency of worker training, job descriptions, 
inspection programs, and statistical control tools (Reid and Sanders, 2002). Some tourism organizations have attained this certification, though its popularity is not as widespread as in other economic sectors.

\section{$\underline{2.3 \text { Customer Perspectives }}$}

Consumers are a great source of feedback for tourism industry practitioners. The results of their attitudes and opinions about the organization will likely result in behaviors to repeat or not to repeat purchases. Therefore, it is important to understand and value their perspectives. Of even greater importance, is to take actions based on their feedback. Many tourism and hospitality organizations collect feedback and report feedback on their customers, but what really happens to such information? In the tourism and hospitality literatures, several researchers have explored the concept of Word-ofMouth (WOM) in general and consumer-generated feedback in specific.

Sundaram, et al. (1998) proposed that consumers engage in positive WOM as a form of altruism, product-involvement, self-enhancement, and helping the company. On the other hand, consumers engage in negative WOM as a means of anxiety reduction, vengeance, altruism, and advice-seeking. When it comes to the restaurant industry, Jeong and Jang (2011) proposed that people are more likely to engage in positive word-of-mouth regarding experiences with superior, food, service and aesthetics. Additionally, some of factors that impact WOM include: the receiver, the strength of the expression, the amount of room for change, whether the WOM is solicited or not, whether the WOM is about the receiver's main brand, and how much WOM was given about a particular category, in addition to age, gender, and product category (East et al., 2008).

One source of WOM, consumer-generated feedback has been the source of several academic publications and much attention by industry practitioners in recent years. In examining the literature on this subject, three streams of research exist: the first emphasizes the role of consumer generated feedback in influencing purchase behaviors (Pavlou \& Dimoka, 2006; Sparks \& Browning, 2011; 
Vermeulen \& Seegers, 2009; Williams, et al., 2010), the second emphasizes the credibility of consumer feedback, and a third stream focuses on the organization's image (Schmallegger \& Carson, 2007, O'Connor, 2010). In spite of the existing literature, studies more research is needed to explore consumer generated feedback alongside other forms of feedback such as those coming from experts and industry practitioners.

Information from consumers can help tourism organizations help track of attitudes, opinions, and satisfaction of guests over time (Schmallegger \& Carson, 2007). Furthermore, reviews can have a financial impact, as they affect customer decision making (Sparks \& Browning, 2011). It has also been established that user-generated feedback is more important to the purchasers of experiential products (Senecal and Nantel, 2004). Researchers have explored the links between culture and the use of consumer-generated feedback. More specifically, Wilson, Murphy, and Fierro (2012) discovered that customers from Switzerland and the United Kingdom were more likely to use social networks to share their vacation experience with friends and family. In contrast, customers from Spain preferred to use TripAdvisor in order to make recommendations to fellow travelers. The reasons for posting may also vary by country of origin (Wilson, et al., 2012).

Many companies choose to respond to the feedback or guest complaints online. When management responds to guest's feedback, it is critical that their responses be specific as opposed to generic (Wei, Miao, \& Huang, 2013). This will make such responses more effective from the customer's perspective. Additionally companies are going beyond responding and also use tools like social networking to encourage guests to share videos, stories, create photo contests, and socialize with other guests (Kasavana et al., 2010). The potential for customer-generated videos can help promote a hospitality business or tourism destination. However, there are concerns that the image such videos 
generate is not the same as the one portrayed by the destination marketers (Lim, Chung, \& Weaver, 2012).

Consumer feedback through online sources can also impact the finances of a company. Ye, Law and Gu (2009) created a mathematical model to measure the impact of consumer-generated media on sales. Accordingly, a $10 \%$ improvement in reviews led to a $4.4 \%$ increase in sales. Other researchers have found a positive relationship between positive reviews and traffic to a restaurant's proprietary website (Zhang, Ye, Law, \& Li, 2011). In addition to the scholarly research, business leaders are also realizing the impact of such feedback. Brian Ferguson (EVP of Expedia) suggested that "[a] one-point increase in a review score equates to a 9\% increase in Average Daily Rate" (Lynch, 2012). From here, it is proposed that consumer-generated feedback can not only be used for marketing, but may also be used for operational improvement (Lynch, 2012).

Researchers in the field of consumer-generated feedback have also explored the top attributes of interests for both hotels and restaurants. According to Ong (2012), customer postings online stress hotel location, room, and value for the price. In contrast, restaurant postings stress the importance of food taste, and customer service. With regards to the usage of positive versus negative reviews, respondents were equally likely to rely on either to make their decision (Ong, 2012). Verbal (text) comments remain more important than quantitative (i.e. score) ratings when gathering information from an online feedback site (Ong, 2012).

User-generated content is used by a variety of travelers. At the present time, user-generated content is more likely to be used by younger people (Vermeulen \& Seegers, 2009). When they are used, only comments from the top two pages are typically considered (Sparks \& Browning, 2011). Usergenerated reviews are an important yet not the sole criteria used by consumers to make a decision (Cox et al., 2009). The literature also suggests that user-generated content is likely to have an impact on 
intention to purchase (Sparks \& Browning, 2011) and room sales (Ye et al., 2009). Today, researchers know some specifics about how people post information on travel websites. For instance, O'Connor (2010) revealed that the typical reviewer in TripAdvisor has posted 4.5 comments and has been active for an average of 10 months at the time of posting. Consumer-generated feedback continues to capture the attention of scholars and practitioners. The present research seeks to contribute to the knowledge in the field and provide additional perspectives in the exploration of various sources of feedback.

\section{Methodology}

\section{$\underline{3.1 \text { Participants }}$}

After an extensive review of the literature and some preliminary interviews, a survey was designed. The survey was pilot tested by several hotel General managers. After pilot testing, the instrument was sent to hotel General Managers, whose properties were rated four and five diamonds by the American Automobile Association (AAA). The AAA list was used for several reasons. First, it provided an extensive list of properties. Second, the list assured that the survey was delivered to upscale hotels, the target of the study. Arguably, upscale hotels face more scrutiny when it comes to their image and quality; thus the study of quality feedback is particularly relevant. Third, the directory provided a list of managers and reduced the bias associated with choosing respondents randomly.

The list of both four and five diamond properties totaled 1,102 hotels. The researchers called each of these hotels and attempted to obtain the name of the General Manager. Most hotels furnished this data, though some did not have a General Manager or were unwilling to provide the information. Consequently, the researchers were able to ascertain a total of approximately 1,000 names and addresses of General Managers. The survey instrument was sent to them using the United States Postal Service. A total of 140 surveys were returned for a response rate of $14 \%$. After completing the survey, General Managers were encouraged to submit their business cards if they were willing to participate in a 
follow-up interview. A total of 33 business cards were received from General Managers. After contacting the General Managers, twelve of them were willing to provide their feedback via interviews.

\subsection{The survey instrument}

The first three survey questions were designed to obtain information about the hotel's monitoring of consumer feedback, the individuals who perform such functions, and the frequency of monitoring. Question four was subdivided into several questions. Essentially, this part of the survey sought to obtain information on the relative value that managers place on consumer feedback. Included in this part were options such as travel websites, social networking sites, and travel blogs, among others. The question was designed on a five-point Likert-type scale ranging from "no value" to "very valuable". Question five inquired about the specific uses General Managers give to the information received from consumers. Some of the uses included making changes in training and development, holding employees and managers accountable, and changing operating procedures. The question was measured on a fivepoint Likert-type scale ranging from "strongly disagree" to "strongly agree". Question six of the questionnaire also attempted to determine if hotels are spending more time reviewing positive or negative feedback.

The second section of the survey addressed the relative importance of various forms of quality control feedback, the General Manager's quality results, and how performance was appraised. To obtain this information, the researchers asked the General Managers to rate the importance of consumer feedback and other criteria used to evaluate their own performance. Question seven obtained quantitative data on this subject through a five-point Likert-type scale ranging from "unimportant" to "very important". One of the concepts for study in the research is that of quality improvement. In hospitality literature, quality has been studied through hotel rating systems, customer satisfaction, mystery shopping, and internal feedback. Question eight sought to obtain information from General 
Managers about how they perceive their hotel's quality to have improved, worsened, or remained the same in each category. Managers were given multiple choice options, in ascending value from "taken a step back" to "highly improved". In some of these questions, managers were given examples about what might constitute improvement.

The ninth question inquired about the importance of consumer feedback in helping hotels improve their performance in several areas including: finances, customer satisfaction, and reviews by experts. Based on the perceptions of the General Manager, this question was measured on a five-point Likert-type scale ranging from "unimportant" to "very important". Likewise, question ten inquired about the General Manager's perception of a relationship between consumer feedback and customer satisfaction scores. General Managers were asked their perceptions about the reliability of different sources of feedback including TripAdvisor, social networking sites, and blogs, among others. The questionnaire concluded by asking several demographic questions to capture the hotel's general characteristics. The third and final section of the survey attempted to obtain demographic information about the hotels. Hotel classifications included independents versus chain-affiliated, AAA diamond rating, Forbes star ratings, and management company status (i.e. managed by corporate, by management company, etc.).

\subsection{Analysis Procedures}

After the data was collected, it was subject to statistical analysis using SPSS 16.0 as the statistical analysis software. The statistical consulting service at Purdue University was used to ensure the adequacy of the statistical procedures utilized. In order to establish the relationship between various variables, the researchers conducted correlation analysis. Accordingly, various correlation matrices were generated. Key relationships were established and reported in the results section. Additionally, 
canonical correlation analysis was utilized to ascertain the grouping of various variables and the relationships.

\section{Results}

During the course of data analysis, several correlation matrices were generated. The first correlation matrix generated was that of perceptions of quality improvement. In the questionnaire, General Managers were asked about the perceptions of the improvement in various quality categories including: AAA diamond ratings, Forbes star ratings, customer satisfaction scores, consumer-generated ratings (i.e. trip advisor, yelp, and similar sites), evaluations from corporate headquarters, and mystery shopper evaluations. The results show that there are moderately positive correlations between AAA scores and customer satisfaction (.322), between AAA and mystery shopping (.396), between Forbes and customer satisfaction (.305), between customer satisfaction and consumer generated ratings (.466), between customer satisfaction and corporate evaluations (.336), between corporate evaluations and mystery shopping reports (.330).

As demonstrated by the correlation matrix in Table 1, General Managers perception of improvement in evaluations from consumers (such as that of customer satisfaction) was closely related to improvement in evaluations offered by experts (such as those offered by rating inspectors and mystery shopping). Furthermore, a moderate correlation existed between online consumer ratings and those of the hotel's proprietary customer satisfaction survey. This will imply that consumers evaluate hotels in similar manner in both online and offline. Whereas some practitioners initially thought consumers might be more critical online, the results from this survey suggest that their responses bear correlation to the surveys that have been the staple of customer engagement measurement for decades. Table 1 presents a correlation matrix of the items related to value placed on consumer feedback. 


\section{〉>Insert Table $1 \ll<<$}

The next correlation matrix generated was that of value placed on feedback by hotel General Managers. The purpose of this question was to ascertain which forms of feedback were valued more by hotel General Managers, and which were perceived to be similar. In the questionnaire, a series of items attempted to measure this variable, including the value placed on feedback from travel feedback site (i.e. Trip Advisor, Yelp and similar), consumer reviews using Online Travel Agencies (OTA), feedback given through social networking sites, blogs, and other more traditional sources of feedback such as letters from customers, in-person guest feedback, and feedback from meeting planners. Several moderate to high correlations were detected. Managers who placed high value on the feedback from travel feedback sites (i.e. expedia, yelp), also placed great value on the feedback from consumers using online travel agencies (.734), social networking sites (.606), and blogs (.525). Those who placed more value on traditional forms of feedback such as letter from customers, also valued in-person feedback (.607) and meeting planner feedback (.310). Based on these results, it seems that two groups of General Managers exist: those who concentrate more on online feedback, and those who emphasize more traditional forms of feedback. Both can arguably be important to hotels today. Whereas in-person complaints and meeting planner feedback represent the items that consumers were willing to directly disclose to the hotel, other forms of feedback, such as those from TripAdvisor can provide additional insight that the hotel might not be aware of. Please view Table 2 for details.

\section{>>Insert Table $2<<<$}

The next correlation matrix attempted to discover the relationships between the various measures for the perceived usefulness of consumer feedback in helping improve performance, including items such as benchmarking, financial data, customer satisfaction, expert reviews, and internal feedback. The results show a moderate positive correlation between performance benchmarking and financial performance (.428). There was also a moderate positive relationship between perceived 
financial performance and customer satisfaction scores (.463). Customer satisfaction scores were positively correlated with internal sources of feedback (.524). The purpose behind these statistics ws to explore the possibility of relationships among various hotel performance criteria. As demonstrated, financial performance bears a moderate correlation with customer satisfaction scores. Therefore, the assumption that keeping customers happy will yield its financial reward held true for the General Managers surveyed. Interestingly, feedback from consumers and from internal sources to the hotel seem to bear a moderate correlation as well. In light of this, General Managers may be able to utilize the advice and feedback of internal stakeholder to improve customer service. Performance items should not be reviewed in isolation, as they tend to vary with each other. Consequently, a strategy that aims at improving overall organizational performance by targeting its different components in an integrated fashion will likely benefit General Managers. Table 3 presents a correlation matrix of the items related to perceived performance.

\section{>>Insert Table $3<<<$}

A correlation matrix was generated for the questions concerning the use of consumer feedback for operations purposes. This matrix contained those items that were considered "systematic" due to their long-term orientation. Such items include changes made to the standard operating procedures (SOP), the usage of feedback to detect both positive and negative patterns of feedback, the modification of training programs, and various quality initiatives. The correlation matrix below shows some moderately positive correlations. Of particular interest is the correlation between using feedback to make changes in operating procedures and using feedback to identify patterns of complaints. Another moderately positive correlation exists between using feedback to train or re-train employees and using feedback to identify patterns of praise. Table 4 presents a correlation matrix of the operational practices resulting from consumer feedback. 


\section{$\gg>$ Insert Table $4<<<$}

Canonical correlation analysis was performed in order to determine the dimensionality of various variables of interest. The researchers used the "manova" syntax in SPSS 16.0 statistical software in order to conduct this analysis. The first set of variables that were subjected to canonical correlation analysis were those of value placed on feedback and management practices. The test of dimensionality for the canonical correlation analysis revealed that one dimension was statistically significant at the .05 level. Please see Table 5 for details. Dimension 1 had a canonical correlation of .48 and a p-value of .00. Standardized canonical coefficients were obtained for both sets of variables (see Table 6). The most influential variables in this dimension in the value column were value placed on TripAdvisor (-.50) and value placed on meeting planner feedback (-.51). These correspond to numbers one and seven in Table 6. The practice of rewarding employees for positive actions (-.63) corresponds to row 2 on the practice column. The canonical correlation analysis seems to confirm what the correlation matrices revealed, in that feedback (in traditional form, electronic form) bears relationship.

\section{〉>Insert Tables 5 \& $6<<<$}

The second set of variables that was subjected to canonical correlation analysis were those of value placed on feedback and quality. The test of dimensionality for the canonical correlation analysis revealed that one dimension was statistically significant at the .05 level. Please see Table 7 for details. Dimension 1 had a canonical correlation of.58 and a p-value of .008. Standardized canonical correlations were obtained. The most influential variables in this dimension were value placed on reviews in TripAdvisor (-.40), value placed on social networking (-1.16), and perceived improvement in consumergenerated ratings (-1.02). All of the influential variable in this dimension are related to online feedback. Online feedback in its various forms can be correlated, as seen in both the correlation and canonical correlation analysis. More on the implications of this in the discussion section. See Table 8 for details. 


\section{>>Insert Tables $7 \& 8<<<$}

\section{Discussion}

In the tourism and hospitality industries, a wealth of information exists that can potentially help operators improve the quality of the services they offered. The current research attempted to explore feedback from consumers, experts, and operators in order to assists in the quality management process. Many operators adopt a piece meal approach, where they attempt to address the various quality challenges separate from one another. The results of this study show moderate correlations among the various elements of consumer and expert feedback, thus practitioners could potentially reap benefits from a more integrated approach.

Correlation Analysis revealed that improvement in one category of feedback often lead to improvement in other categories. More precisely AAA diamond ratings were closely related to a hotel's improvement in terms of customer satisfaction and mystery shopping scores. Some mystery shoppers use systems for evaluation that can be compared to those of rating inspectors. Therefore, this particular result comes as no surprise. Indeed, hoteliers can use the information from mystery shoppers to help prepare for their rating evaluation. Attaining a diamond rating can also be a good way to ensure customer satisfaction. Forbes' star ratings were also moderately correlated to customer satisfaction. By ensuring compliance with the standards of rating agencies, operators can ensure a certain level of quality that would lead to customer satisfaction. Experts and consumers can place value on different aspects of a service experience. However, given the moderate correlation between these two scores, this may imply that certain universal standards of service might be important to both consumers and experts. Future research could further explore the criteria by which consumers and experts evaluate hotels. 
Customer satisfaction and consumer generated ratings had a moderate correlation (.466). This result is particularly relevant, as some have questioned the legitimacy of consumer generated feedback and the potential for dishonest reviews has always existed. In spite of this, it seems that customer satisfaction scores from the hotel's internal survey closely match variations in consumer generated ratings given through feedback sites such as TripAdvisor and Yelp. Therefore, efforts to improve one, could aid in improving the other. In other words, the feedback given by consumers online could help hotels improve the customer satisfaction score and the feedback given by customers through surveys can potentially aid hoteliers in improving their image in various travel sites. It has been proposed that consumer-generated feedback can impact a hotel's bottom line and traffic to its proprietary website (Yet, et al., 2009; Zhang, et al., 2011). In light of this, a strategy to monitor feedback can prove beneficial for hospitality organizations.

Overall General Managers seem to prefer more traditional forms of feedback such as in-person, and letters from customers. Based on the results of the present research, it also appears that when evaluating feedback there are two groups of hotel operators: those who highly value online feedback, and those who prefer traditional forms of feedback. The correlation analysis demonstrated that those who value consumer feedback through travel sites such as TripAdvisor also placed great emphasis on feedback received through online travel agencies, social networking sites, and blogs. Some General Managers are very much aware of the importance of managing their image online and using the various sites to collect information that will help improve the quality of their services.

Operators can use consumer feedback for various purposes. The present study sought to understand whether hoteliers use such information in order to make changes in standard operating procedures, establish patterns of positive and negative feedback, modify training programs, and improve overall quality. Claver-Cortes, et al. (2007) discovered that hotels with great service quality 
often had advanced training and development systems. Consequently, General Managers can use the feedback from consumer-generated feedback to train or re-train their staff in various aspects of customer service.

Many General Managers stress negative feedback over positive. This is in contrast with consumers, who seem to review both positive and negative comments equally (Ong, 2012). Moderate correlations were found between the usage of feedback for training and its use to change standard procedures (.364), negative patterns of feedback (.326) and positive patterns of feedback (.466). A moderate correlation was also found between establishing patterns of negative feedback and patterns of positive feedback (.520). Based on these results, it seems that hoteliers use the feedback in various forms. Those who look for patterns in the data, are also more likely to use it to make longer-lasting change in organizations such as changes to training and development programs. In today's fast-changing industry, it is necessary to make constant adjustments to the service delivery strategy. Schmallegger and Carson (2007) proposed that online feedback can help hospitality and tourism organizations help track of attitudes, opinions, and satisfaction of guests over time. Consumer-generated feedback can provide yet another source of timely feedback that can help organizations better understand their customers. However, such feedback often contains vast amounts of information, thus making it even more critical to develop systems to collect, analyze, and take actions based on such information. Given a dynamic business environment, timely feedback can become an important source of information. Even more critical is what is done with such information. By adopting appropriate strategies, tourism and hospitality operators can reap the rewards of their efforts towards attain better service quality.

\section{Limitations}

The present study used a survey methodology to collect data from hotel General Managers. Although operators are aware of their hotel's strengths and weaknesses, their perceptions and biases 
can also exert an influence over their evaluation of their own quality. Since the study is largely based on the General Manager's perceptions, it's exploratory in nature and thus more research could assist in further understanding the topic. The study only used upscale hotels ( 4 and 5 diamond). Such hotels were targeted due to their constant need to provide quality in order to sustain such high ratings. Nevertheless, other hotels also receive feedback from various sources. Therefore, the perception of select or limited service hotels is not reflected on this particular study. The present research targeted one sector of the hospitality industry: hotels. More research on this subject could target other hospitality and tourism venues such as restaurants, parks, and other attractions.

\section{Practical Implications}

During the course of this study, the researchers have explored the use of various sources of feedback (i.e. experts, operators, and customers) in order to improve service quality. Many General Managers are placing value and attention to electronic sources of feedback. Yet, a significant group of practitioners still places more value on traditional sources of feedback such as letters from customers. Given the growing number of online reviews, it is imperative that all managers learn about the best ways to collect, analyze, and use the data. A comprehensive strategy can be adopted to process consumer generated feedback along with other sources of information together. Such strategy can point out to commonalities and differences in the perceptions of the service experience as provided by various stakeholders.

The researchers discovered that improvement in one area of service can lead to improvement in others. It is therefore incumbent upon practitioners to examine all forms of feedback and determine what strategies could yield the greatest improvement across the board. In spite of these findings, the actions taken by hotel General Managers can be quite different. In many cases, collecting the data and 
reporting it is the extent of a hotel's consideration to consumer feedback. Actions can be taken to ensure the continuance of those positive comments and the dissipation of negative ones. By making changes to training practices, and operating procedures, managers can ensure that their efforts in monitoring feedback pay off. 


\section{References}

Adebanjo, D., Abbas, A., Mann, R. (2009), “An investigation of the adoption and implementation of benchmarking”, International Journal of Operations \& Production Management, Vol. 30 No. 11, pp. 1140-1169.

Ante, S. (2007, August 30). "Six Sigma Kick-Starts at Starwood". BusinessWeek. Available at: http://businessweek.com (Accessed on 22 June 2012)

Beck, J., \& Miao, L. (2003), “Mystery shopping in lodging properties as a measurement of service quality", Journal of Quality Assurance in Hospitality and Tourism, Vol. 4 No. 1/2, pp. 1-21.

Behara, R., \& Lemmink, J. (1997), "Benchmarking field services using a zero defects approach", International Journal of Quality \& Reliability Management, Vol. 14 No. 5, pp. 512-516.

Callan, R. (1990), “Hotel award schemes as a measurement of service quality - An assessment by travel industry journalists as surrogate consumers", International Journal of Hospitality Management, Vol. 9 No. 1, pp. 45-58.

Carrillat, F. Jaramillo, F., \& Mulkim J. (2009), “Examining the impact of service quality: A meta-analysis of empirical evidence", Journal of Marketing Theory and Practice, Vol. 17, No. 2, pp. 95-110.

Chand, M., \& Catou, A. (2007), "The impact of HRM practices on organizational performance in the Indian hotel industry", Employee Relations, Vol. 29 No. 6, pp. 576-594.

Claver-Cortes, E., Pereira-Moliner, J., Tari, J., \& Molina-Azorin, J. (2007), “TQM, managerial factors, and performance in the Spanish hotel industry", Industrial Management and Data Systems, Vol. 28 No. 2, pp. 228-244.

Cox, C., Burgess, S., Sellito, C., \& Buultjens, J. (2009), "The role of user-generated content in tourists' travel planning behavior", Journal of Hospitality Marketing \& Management, Vol. 18, pp. 746764. 
Crick, A., \& Spencer, A. (2011), "Hospitality quality: New directions and new challenges", International Journal of Contemporary Hospitality Management, Vol. 23 No. 4, pp. 463-478.

Cronin, J., and Taylor, S. (1992), "Measuring service quality: A reexamination and extension”, Journal of Marketing, Vol. 56 No. 3, pp. 55-68.

East, R., Hammond, K., \& Lomax, W. (2008), “Measuring the impact of positive and negative word of mouth on brand purchase probability", International Journal of Research in Marketing, Vol, 25, pp. 215-224.

Enz, C., \& Siguaw, J. (2000), "Best practices in service quality”, Cornell Hospitality Quarterly, Vol. 41 No.5, pp. 20-29.

Enz, C., \& Siguaw, J. (2003), "Revisiting the best of the best: Innovations in hotel practice", Cornell Hospitality Quarterly, Vol. 44 No. 5/6, pp. 115-123.

Grobelna, A. \& Marciszewska, B. (2013), “Measurement of service quality in the hotel sector: the case of Northern Poland", Journal of Hospitality Marketing and Management, Vol. 22 No. 3, pp. 313332.

Hwang, L., \& Lockwood, A. (2006), “Understanding the challenges of implementing best practices in hospitality and tourism SMEs", Benchmarking: An International Journal, Vol. 13 No.3, pp. 337354.

Jeong, E., \& Jang, S. (2011), “Restaurant experiences triggering positive electronic word-of-mouth (eWOM) motivations", International Journal of Hospitality Management, Vol. 30, pp. 356-366.

Kasavana, M., Nusair, K., \& Teodosic, K. (2010), “Online social networking: Redefining the human web”, Journal of Hospitality and Tourism Technology, Vol. 1 No. 1, pp. 68-82. 
Kim, H. (2011). "Service orientation, service quality, customer satisfaction, and customer loyalty: Testing a structural model", Journal of Hospitality Marketing and Management, Vol. 20 No. 6, pp. 619637.

Knutson, B., Beck, J., Kim, S., \& Cha, J. (2010). “Service quality as a component of the hospitality experience: Proposal of a conceptual model and framework for research", Journal of Foodservice Business Research, Vol. 13, No. 1, pp. 15-23.

Lim, Y., Chung, Y., Weaver, P. (2012), "The impact of social media on destination branding: Consumergenerated videos versus destination marketer-generated videos", Journal of Vacation Marketing, Vol. 18 No. 3, pp. 197-206.

Luchars, J. Y., \& Hinkin, T. R. (1996), "The service-quality audit: A hotel case study", Cornell Hospitality Quarterly, Vol. 37 No. 1, pp. 34-41.

Lynch, J. (2012, January 10), "Online review reputation management trends for hotels in 2012". Sabre Hospitality Solutions. Available at: http://www.sabrehospitality.com/blog (accessed on 6 February 2012).

Mason, M., \& Nassivera, F. (2013), “A conceptualization of the relationships between quality, satisfaction, behavioral intention, and awareness of a festival", Journal of Hospitality Marketing and Management, Vol. 22 No. 2, pp. 162-182.

McGaughey, R. (2002), “Benchmarking business-to-business electronic commerce”, Benchmarking: An International Journal, Vol. 9 No. 5, pp. 471-484.

Min, H., \& Min, H. (1996), "Benchmarking the quality of hotel services: Managerial perspectives", International Journal of Quality and Reliability Management, Vol. 14 No. 6, pp. 582-597. Min, H., Min, H., \& Chung, K. (2002), "Dynamic benchmarking of hotel service quality", Journal of Services Marketing, Vol. 16 No. 4, pp. 302-321. 
Narangajavana, Y., \& Hu, B. (2008), "The relationship between the hotel rating system, service quality improvement, and hotel performance changes: A canonical analysis of hotels in Thailand", Journal of Quality Assurance in Hospitality\& Tourism, Vol. 9 No.1, pp. 34-56.

NIST. (n.d.). Available at: http://www.quality.nist.gov/Ritz_Carlton_Hotel_Co.htm (Accessed on 12 March 2012)

O'Connor, P. (2010), "Managing a hotel's image on TripAdvisor", Journal of Hospitality Marketing \& Management, Vol. 19, pp. 754-772.

Ong, B. (2012), "The perceived influence of user reviews in the hospitality industry", Journal of Hospitality Marketing \& Management, Vol. 21 No. 5, pp. 463-485.

Parasuraman, A., Zeithaml, V., \& Berry, L. L. (1988), "SERVQUAL: A multiple-item scale for measuring consumer perceptions of service quality", Journal of Retailing, Vol. 64 No. 1, pp. 1240.

Pavlou, P. A., \& Dimoka, A. (2006), "The nature and role of feedback text comments in online marketplaces: Implications for trust building, price premiums, and seller differentiation", Information Systems Research, Vol. 17 No. 4, pp. 392-414.

Reid, R. D., \& Sanders, N. R. (2002). Operations management, John Wiley \& Sons, New York.

Salazar, A., Costa, J., \& Rita, P. (2010), "A service quality evaluation scale for the hospitality sector", Worldwide Hospitality and Tourism Themes, Vol. 2 No. 4, pp. 383-397.

Schmallegger, D., \& Carson, D. (2007), "Blogs in tourism: Changing approaches to information exchange", Journal of Vacation Marketing, Vol. 14 No.2, pp. 99-110.

Senecal, S., \& Nantel, J. (2004), “The influence of online product recommendations on consumers' online choices", Journal of Retailing, Vol. 80, pp. 159-169.

Sparks, B. A., \& Browning, V. (2011), "The impact of online reviews on hotel booking intentions and perception of trust", Tourism Management, Vol. 32 No. 6, pp. 1310-1323. 
Su, C. S., \& Sun, L. H. (2007), "Taiwan's hotel rating system: A service quality perspective", Cornell Hotel and Restaurant Administration Quarterly, Vol. 48 No. 4, pp. 392-358.

Sundaram, D., Mitra, K., \& Webster, C. (1998), "Word-of-mouth communications: A motivational analysis", Advances in Consumer Research, Vol. 25, pp. 527-531.

Torres, E., Kline, S. (2013), "From customer satisfaction to customer delight: Creating a new standard of service for the hotel industry". International Journal of Contemporary Hospitality Management.

Van Der Wiele, T., Hesselink, M., Van Iwaarden, J. (2005). "Mystery Shopping: A tool to develop insight into customer service provision". Total Quality Management, Vol. 16 No. 4, pp. 529-541.

Vermeulen, I. E., \& Seegers, D. (2009), "Tried and tested: The impact of online hotel reviews on consumer consideration", Tourism Management, Vol. 30, pp. 123-127.

Wei, W., Miao, L., Huang, Z. (2013), “Customer engagement behaviors and hotel responses”, International Journal of Hospitality Management, Vol. 33, pp. 316-330.

Williams, R., Van der Wiele, T., Van Iwaarden, J. , \& Eldridge, S. (2010), „The importance of usergenerated content: The case of hotels", The TQM Journal, Vol. 22 No. 2, pp. 117-128.

Wilson, A., Murphy, H., Fierro, J. (2012), “Hospitality and travel: The nature and implications of usergenerated content", Cornell Hospitality Quarterly, Vol. 53 (3), pp. 220-228.

Wong, I., \& Fong, V. (2010), “Examining casino service quality in the Asian Las Vegas: An alternative approach", Journal of Hospitality Marketing and Management, Vol. 19 No. 8, pp. 842-865.

Yang, C., \& Lu, W. (2006), "Performance benchmarking for Taiwan's international tourist hotels", INFOR, Vol. 44 No. 3, pp. 229-245.

Yasin, M., \& Zimmerer, T. (1995), "The role of benchmarking in achieving continuous service quality", International Journal of Contemporary Hospitality Management, Vol. 7 No. 4, pp. 27-32.

Ye, Q., Law, R., \& Gu, B. (2009), "The impact of online user reviews on hotel room sales", International Journal of Hospitality Management, Vol. 28, pp. 180-182. 
Zhang, Z., Ye, Q., Law, R., \& Li, Y. (2011), “The impact of e-word-of-mouth on the online popularity of restaurants: A comparison of consumer reviews and editor reviews", International Journal of Hospitality Management, Vol. 29 No. 4, pp. 694-700. 